\title{
Managerial and Disciplinary Constraints Applied to Faculty Staffing
}

CHARLES H. BELANGER, PH. D.

\begin{abstract}
The purpose of this study was to determine whether the same faculty members would be dismissed when faculty staffing decisions were based solely on institutional personnel management constraints as when the decisions were further constrained to preserve disciplinary integrity. Two sets of constraints were entered into an integer linear programming model to assess the effect on the structural integrity of a discipline and on the allocation of faculty resources when a 20 percent budget reduction was simulated.

After collecting actual data from six academic departments at Florida State University, the analysis of the results led to the conclusion that each department chairman needed to structure his discipline into discipline elements, determine the basic number of positions essential to given identity to each discipline element, and protect the key specialists who filled those positions regardless of their teaching assignments. The number of such positions must be very limited to avoid losing the financial stability of the department in steady-state conditions and being lock-steppped in times of budgetary restrictions.
\end{abstract}

\section{RÉSUMÉ \\ Contraintes administratives et disciplinaires appliquees a l'allocation des ressources du personnel enseignant}

Cette étude avait pour but de déterminer si les mêmes postes de professeurs devaient être abolis quand les décisions concernant le personnel enseignant ne reposaient que sur des contraintes de gestion de personnel institutionnel ou guand les décisions étaient prises d'abord pour préserver l'intégrité disciplinaire. Deux ensembles de contraintes furent appliqués à un modèle de programmation linéaire entier pour estimer l'effet simulé d'une réduction de $20 \%$ du budget sur l'intégrité structurelle d'une discipline et sur l'allocation des ressources du personnel enseignant.

La cueillette des données fut effectuée auprès de six (6) départments académiques à 
Florida State University; l'analyse des résultats a amené à conclure que chacun des directeurs de département devrait structurer sa discipline en éléments disciplinaires D'une part, déterminer le nombre minimal des postes essentiels pour préserver et développer chacun des éléments disciplinaires d'autre part et, enfin, protéger les spécialistes-clés qui remplissent ces postes, indépendamment de leur charge d'enseignement. Le nombre de ces postes doit de plus être limité si l'on veut éviter le déséquilibre financier du département en période de ressources stables et bénéficier d'une marge de manoeuvre, si petite soit-elle, en temps de restrictions budgétaires.

\section{INTRODUCTION}

Faculty staffing in postsecondary education institutions is an activity that has contributed more than its share to creating and maintaining a climate of tense coexistence among parties involved in academic administration. During the growth phase, accommodations were more easily arrived at by distributing incremental funds to departments and schools that exhibited the most growth. Canadian institutions are presently operating in a context of gradual consolidation where the curtailment of government expenditures, collective bargaining pressures, and an aging professoriate have taken away most of the flexibility enjoyed in the golden years. These new constraints must now be analyzed in terms of their consequences for academic vitality and financial stability. American institutions have experienced many of these constraints before their Canadian counterparts; they have clearly indicated the way they intended to go by fighting court battles over the dismissal of non-tenured as well as tenured faculty members for economic reasons. Therefore, in a time where personnel action demanded by lack of resources and other societal pressures has become more frequent, criteria for recruiting and dismissing faculty members must become clearer in order to preserve the institutional mission and meet the changing needs of society. Administrators who must satisfy these changing and often conflicting conditions need to establish a dynamic priority system if their accountability eff $\sim$ rts are to be credible. one way to establish such a system is to view the recruitment and dismissal of faculty members as a problem of optimizing salary dollars to meet both institutional management objectives and to advance each discipline in a way that is academically respectable.

The purpose of this study was three-fold:

1. To examine whether the same faculty members would be dismissed when faculty staffing decisions were based solely on institutional personnel management constraints as when the decisions were further constrained to preserve the structural integrity of a discipline;

2. To determine whether the allocation of faculty based solely upon the solution of an integer linear programming equation using institutional personnel management constraints would yield the same allocation when the integer linear programming model used both institutional personnel management and disciplinary constraints;

3. To provide an operational frame of reference on financial exigency as it related to faculty reduction and reallocation in the academic disciplines.

The considerable growth of postsecondary education in the 1960's gave rise to the 
development and implementation of a wide variety of models in North America (20) as well as overseas $(12,13,14,15)$. While these "relatively new" administrative and managerial tools were being experimented, (16) the changing conditions of the 1970's were calling for a second generation of models to complement the descriptive models of the first generation. These second generation models would provide heuristic and optimizing capabilities, and would incorporate benefit values as well as costs (7). Of particular interest to administrators was the fact that optimization techniques were decision-oriented and could consider conflicting and competing demands simultaneously.

A number of investigators have labored on the application of mathematical programming techniques to faculty-related problems $(17,10,2.22,18,1,4,6,21,8)$. Several of these studies have covered from one angle or another most of the managerial constraints exposed in the following section of this paper. However, little attention has been given to the impact of disciplinary constraints upon models used to optimize faculty resource allocation. This preoccupation has become most important since many institutions have had to face faculty retrenchment to avoid financial disaster. In a context of curtailment, there is a great danger of damaging the structural integrity of a discipline if precautionary measures are overlooked.

\section{METHOD}

\section{Propositions}

The following propositions constituted the areas of investigation of this study:

Proposition 1. The structural integrity of an academic discipline is weakened when the selection of faculty members to be terminated is based solely upon the solution of an integer linear programming equation using institutional personnel management constraints.

Proposition 2. The allocation of faculty based solely upon the solution of an integer linear programming equation using institutional personnel management constraints yielded the same allocation when the integer linear programming model used both institutional personnel management and disciplinary constraints.

\section{Test on Proposition 1}

In order to test whether academic disciplines were weakened by the conditions stated in proposition 1, the following steps were taken:

1. Each discipline was divided into its discipline elements.

2. Each regular faculty member was identified with one discipline element within the discipline under study.

3. Each regular faculty member was classified either as key specialist or specialist. The key specialist was defined as the leading authority of a discipline element in his/her department while the specialist was a person whose position was secured by enrollment.

4. A uniform budget cut was simulated in each of the selected departments. (The magnitude of the simulated budget cut represented a search for a number that would affect at least one key specialist in each discipline.) 
5. An integer linear programming equation using institutional personnel management constraints was solved to maximize the number of academic positions to be retained.

6. In order to define operationally the weakness of an academic discipline, a search was made for a budget reduction that would affect at least one key specialist in each discipline as solved by the linear programming model, and would lead to the rejection of proposition 1 .

\section{Test on Proposition 2}

In order to determine whether faculty termination decisions made under the two sets of conditions stated in proposition 2 , resulted in the same allocation, the following steps were taken:

1. The same institutional personnel management constraints used in proposition 1 were plugged into the model.

2. In addition, disciplinary constraints were also built into the model.

3. The integer linear programming equation was solved for each discipline with the same uniform budget cut as the one found in the solution of proposition 1.

4. If the solution obtained when using both institutional personnel management and disciplinary constraints resulted in the same number of retained academic positions as the solution obtained when using solely institutional personnel management constraints, proposition 2 would be discarded.

\section{Integer Linear Programming Model}

Since the integer linear programming model that was used to solve the maximization problem of this investigation fell in the decision model family, it seemed appropriate to give a brief description of the general decision model form. Decision models have two essential characteristics: (a) there must be at least one of the input variables that is controllable by the decision maker in order to provide more than one alternative course of action; and (b) the output variables must measure the value of the alternative choices available to the decision maker (9).

In addition to the basic form $\left(\mathrm{V}=\mathrm{f}\left(\mathrm{X}_{\mathrm{i}}, \mathrm{Y}_{\mathrm{j}}\right)\right.$ ) of the general decision model, the standard linear programming model has three other characteristics: (a) an objective function which is to be maximized for minimized; (b) structural constraints which are imposed on the decision variables; and (c) non-negativity conditions which are also imposed on the decision variables. For certain types of problems, fractional answers are inconvenient or even meaningless. When this situation arises, a special case of linear programming, called integer linear programming, must be introduced. In this study, the decision variables represented academic positions filled by individuals. The decision variables were not only integers, but actually O's and I's as were required for a meaningful answer. Consequently, the integer linear programming model was represented by the following standard system of mathematical relationships:

$$
\begin{array}{ll}
\text { Maximize } & z=c_{1} x_{1}+c_{2} x_{2}+\ldots+c_{j} x_{j}+\ldots+c_{n} x_{n} \\
\text { Subject to } & a_{11} x_{1}+a_{12} x_{2}+\ldots+a_{1 j} x_{j}+\ldots+a_{1 n} x_{n} \leq b_{1} \\
& a_{21} x_{1}+a_{22} x_{2}+\ldots+a_{2 j} x_{j}+\ldots+a_{2 n} x_{n} \leq b_{2}
\end{array}
$$




$$
\begin{aligned}
& a_{i 1} x_{1}+a_{i 2} x_{2}+\ldots+a_{i j} x_{j}+\ldots+a_{i n} x_{n} \leq b_{i} \\
& a_{m 1} x_{1}+a_{m 2} x_{2}+\ldots+a_{m j} x_{j}+\ldots+a_{m n} x_{n} \leq b_{m}
\end{aligned}
$$

where

$$
\begin{aligned}
& 0 \leq x_{j} \leq 1 \quad j=1,2, \ldots, n \\
& x_{j}=\text { integer } \\
& n=\text { number of decision variables } \\
& m=\text { number of constraints. }
\end{aligned}
$$

In vector notation, the integer linear programing model had the following form:
$C X=Z$
(Objective Function)
$A X<B$
(Constraint Set)
$x=0$ or 1
(Non-regativity \& Integer-Valued Restriction)

\section{Problem Set Up}

The problem under investigation arose when adjustments needed to be made in the number of academic positions. A severe financial situation was simulated in each of the six selected departments, forcing the department chairmen to reduce the number of their respective faculty members. This reduction was to take place in such a way that the maximum number of faculty members would be retained within certain established managerial and disciplinary constraints.

Objective Function - The objective function was of the maximization type and was stated as:

$$
z_{\max }=x_{j}+x_{2}+\ldots+x_{j}+\ldots+x_{n}
$$

where $\quad z_{\max }=$ the number of faculty members retained.

$$
j=\text { the } j \text {-th faculty member. }
$$$$
n=\text { the number of faculty members in each department. }
$$

$$
\begin{array}{ll}
\text { subject to } & 0 \leq x_{j} \leq 1 \\
& x_{j}=\text { integer. }
\end{array}
$$

Contraints. The testing of the two working propositions exposed in the early part of the methodology section required the development of two sets of constraints. The first series of constraints was exclusively related to institutional personnel management objectives, whereas the second series consisted of the disciplinary constraints. The description of the institutional personnel management constraints was as follows: 

Budget $\quad=$ Total faculty salary dollars after departmental budget reduction
Race $\quad=$ Proportion between blacks and whites within each discipline*
Sex $\quad=$ Proportion between males and females within each discipline*
Tenure $\quad=$ Proportion between tenured and non-tenured faculty members within each department
Rank $\quad=$ Proportion between professors + associate professors and assistant professors + instructors within each department
Instruction $=\mathrm{FTE} / \mathrm{SCH}^{* *}$ instruction productivity expected in each department
Research $\quad=\mathrm{FTE} / \mathrm{SCH}$ research productivity expected in each department
Public service $=$ FTE $/ \mathrm{SCH}$ public service productivity expected in each department
Advisement $=\mathrm{FTE} / \mathrm{SCH}$ advisement productivity expect in each department
Administration $=\mathrm{FTE} / \mathrm{SCH}$ administration productivity expected in each department.
These institutional personnel management constraints were expanded as follows:

Let $S_{j}$ be the salary of the $j$-th faculty member

$$
s_{1} x_{1}+\ldots+s_{j} x_{j}+\ldots+s_{n} x_{n} \leq \text { Budget }
$$

Let $R_{j}$ be the race of the $j$-th faculty member

where $\quad R_{j}=1$ for non-minority faculty members

$R_{j}=0$ for minority faculty members

$$
\begin{aligned}
& R_{1} x_{1}+\ldots+R_{j} x_{j}+\ldots+R_{n} x_{n} \leq \text { Race } \%\left(x_{1}+\ldots .\right. \\
& \left.+x_{j}+\ldots+x_{n}\right)
\end{aligned}
$$

Let $F_{j}$ be the sex of the $j$-th faculty member

where $\quad F_{j}=1$ for male faculty members

$F_{j}=0$ for female faculty members

$F_{1} X_{1}+\ldots+F_{j} X_{j}+\ldots+F_{n} X_{n} \leq \operatorname{Sex} \%\left(X_{1}+\ldots\right.$

$\left.+x_{j}+\ldots+x_{n}\right)$

Let $T_{j}$ be the tenure status of the $j$-th faculty member

where $\quad T_{j}=1$ for tenured faculty members

$T_{j}=0$ for non-tenured faculty members

$T_{1} x_{1}+\ldots+T_{j} x_{j}+\ldots+T_{n} x_{n} \leq$ Tenure $\%\left(x_{1}+\ldots\right.$

$\left.+x_{j}+\ldots+x_{n}\right)$

*Proportions were determined from national data for each discipline in compliance with Equal Employment Opportunity regulations.

${ }^{* * F T E} / S C H=$ Full Time Equivalent/Student Credit Hour 


\section{Managerial and Disciplinary Constraints Applied to Faculty Staffing}

Let $P_{j}$ be the professorial rank of the $j$-th faculty member

where $\quad P_{j}=l$ for professors and associate professors

$P_{j}=0$ for assistant professors and instructors

$$
\begin{aligned}
& P_{1} X_{1}+\ldots+P_{j} x_{j}+\ldots+P_{n} X_{n} \leq \operatorname{Rank} \%\left(x_{1}+\ldots\right. \\
& \left.+x_{j}+\ldots+x_{n}\right)
\end{aligned}
$$

Let $\mathrm{H}_{j}$ be the FTE/SCH instruction productivity of the $j$-th faculty member

$$
\mathrm{H}_{1} \mathrm{X}_{1}+\ldots+\mathrm{H}_{j} \mathrm{X}_{j}+\ldots+\mathrm{H}_{n} \mathrm{X}_{n} \geq \mathrm{FTE} / \mathrm{SCH} \text { instruction }
$$

productivity expected in each department

Let $D_{j}$ be the FTE/SCH research productivity of the $j$-th faculty member $D_{1} X_{1}+\ldots .+D_{j} X_{j}+\ldots+D_{n} X_{n} \geq F T E / S C H$ research productivity expected in each department

Let $L_{j}$ be the FTE/SCH public service productivity of the $j$-th faculty member

$L_{l} X_{1}+\ldots+L_{j} X_{j}+\ldots+L_{n} X_{n} \geq$ FTE/SCH public service

productivity expected in each department

Let $Q_{j}$ be the FTE/SCH advisement productivity of the $j$-th faculty member $Q_{1} X_{1}+\ldots+Q_{j} X_{j}+\ldots+Q_{n} X_{n} \geq$ FTE/SCH advisement productivity expected in each department

Let $v_{j}$ be the FTE/SCH administration productivity of the $j$-th faculty member $v_{1} x_{1}+\ldots+v_{j} x_{j}+\ldots+v_{n} x_{n} \geq F T E / S C H$ administration productivity expected in each department.

In addition to institutional personnel management constraints, disciplinary constraints were imposed on each of the selected disciplines. These constraints were summarized as follows:

Let $k_{j}$ be any key specialist as identified by the department chairman where $\quad k_{j}=1$

$k_{1} x_{1}+\ldots+k_{j} x_{j}+\ldots+k_{n} x_{n}=$ Total number of key specialists to $2 e$ protected to preserva the integrity of the discipline. 


\section{Data Collection and Treatment}

Data were collected from six academic departments at Florida State University. These departments were: Chemistry, English, History, Mathematics, Philosophy and Psychology. For each of these six academic disciplines actual data were collected and categorized in three broad areas: (1) personal information on each faculty member's attributes (salary, race, sex, tenure, and rank status); (2) FTE/SCH productivity of each faculty member (instruction, research, public service, advisement, and administration); and (3) data conducive to the development of disciplinary constraints (division of each discipline into its discipline elements, identification of each regular faculty member with one discipline element, and classification of each regular faculty member as a key specialist or a specialist). As opposed to the left-hand-side of the equations and inequalities in which actual departmental data were plugged, the right-hand-side consisted of standard ("ought to") data. These standards were established either from institutional policies (salary, tenure, rank), discipline particularities (race, sex, key specialists), or Board of Regents budgeting formulas (productivity factors).

To provide readers with more insight on the productivity area, it is worth mentioning that in the state of Florida, each academic department is recognized five productivity activities: instruction, research, public service, advisement, and administration. Instruction is the only activity from which research, public service, advisement, and administration positions are generated. Theoretically, when an FTE position is granted to a department, this FTE position is expected to cover all of the five productivity activities according to specific proportions for each activity. The formula shows that 1.0 FTE postion is expected to be approximately assigned as follows: .78 for instruction, .10 for research, .02 for public service, .06 for advisement, and .04 for administration. Even though the proportions are not expected to be respected for each faculty member, the department as a whole is held responsible to meet productivity standards not only over all activities, but also within each activity. For each of the productivity activities, the actual data had to meet a higher than or equal to $(\geqslant)$ type of constraint. This measure was found necessary to make sure that each of the five activities would be the least damaged by the termination of certain faculty members.

Collected data were entered into an optimizing model called NYBLPC and developed by Dr. Stanley Zionts of the Department of Management Science, State University of New York at Buffalo. The Program was designed to solve standard linear programming problems with a matrix of coefficients not exceeding $100 \times 100$. To serve the specific purpose of this study, additional constraints were incorporated so as to find an optimal solution with variable of O's or I's. The program solved the problem by means of the crisscross algorithm.

\section{ANALYSIS OF RESULTS}

The lowest uniform budget cut that affected at least one key specialist in each of the disciplines surveyed was found to be 20 percent. This process was accomplished by incorporating the institutional personnel management objectives in the integer programming model and by checking if any of the key specialists was affected by this budget reduction. By taking the mathematics faculty as a prototype, the magnitude of the 
damage done to the discipline and its discipline elements (Algebra, Applied Mathematics, Differential Equations, Functional Analysis, and Topology) could be readily assessed. Out of 10 faculty members identified as key specialists by the department chairman, 5 would have been forced to leave if the institutional personnel management criteria had been the only ones to be optimized. This situation arose because key specialists were prestigious faculty members with either an impressive publications record or other accomplishment highly recognized by the academic community. Even though their FTE productivity was comparable to that of the specialists, their higher salaries created an imbalance and made many of them emerge from the optimizing model. In most cases, their productivity would have had to be two or three times higher than the expected productivity standard in order to be on the same level as a faculty member receiving the average faculty compensation and producing the expected standard. Such expectations would have overshadowed the reason for key specialists being brought in.

A second computer run was simulated with the addition of the disciplinary constraints. As this step consisted essentially of protecting the key specialists to preserve the structural integrity of the discipline, the specialists became the ones whose positions had to be terminated. Because a specialist position was required to satisfy a larger enrollment in-flow, the termination of such a position was not expected to endanger the vitality of the discipline and the department as it would have been the case with key specialist positions. Therefore, in a situation where a department had to optimize its reduced resources within managerial and disciplinary constraints, those faculty members who contributed the least to the optimality objectives were the most severely affected. The addition of disciplinary constraints resulted in a definite trend toward increasing the number of academic positions to be terminated. To answer specifically Proposition 2, the mean differential of faculty allocation without and with disciplinary constraints was found to be 1 across the six disciplines investigated. For a more detailed presentation and discussion of the results, interested readers should refer to Belanger (3).

From the department standpoint, it was obvious that the chairman needed to analyse carefully the discipline elements to be covered and determine the number of key specialists needed. This managerial strategy was required for three main purposes: (a) the department chairman wanted to maintain the vitality of his discipline regardless of financial exigency or other constraints; (b) the department could afford only a limited number of faculty members whose productivity was out of balance with their salaries; and (c) the department could secure only a limited number of positions which did not depend upon student enrollment. Whenever the department chairman was lock-stepped in his decisions because he did not have control of the three purposes enumerated above, either the department or the discipline or both were bound for a crisis.

A further analysis of the affected specialists' characteristics gave the perspective of difficult decisions, in the event of a severe budget cut. On the one hand, the department had to optimize its scarce resources within institutional personnel management and disciplinary constraints by eliminating those faculty members who contributed the least to the optimality objectives. On the other hand, the AAUP operating guidelines on financial exigency stipulated that "the service of a tenured professor should not be terminated in favor of retaining someone without tenure who may at a particular moment seem to be more productive (11)." As it turned out in the departments under study, the affected 
specialists had every characteristic of the key specialists except that they were not considered as critical to the integrity of a discipline element. In these very instances, the issue at stake was whether these departments would elect to jeopardize the vitality and even the existence of their academic programs, lose balance on several faculty attributes, and shatter their fragile financial stability, by retaining highly paid and consequently underproductive faculty members. In light of the recent court decisions involving financial exigency cases, a rationale based on the disciplinary and institutional personnel management constraints developed in this study could help a department chairman to document adequately his staffing decisions.

\section{CONCLUSION AND IMPLICATIONS}

The main purpose of this study was to determine whether academic disciplines were weakened by a departmental budget cut necessitated by financial exigency. Institutional personnel management and disciplinary constraints were developed and built into a mathematical programming model. The most important findings were summarized as follows:

1. Disciplines were weakened when staffing decisions were based only on institutional personnel management constraints. Generally speaking, those faculty members who were identified as critical to preserve the integrity of the discipline were very heavily affected.

2. In a few instances, all the key specialists needed to preserve a discipline element were affected, therefore leaving unprotected this particular discipline element.

3. When disciplinary constraints were added, the number of dismissed faculty members increased.

4. When key specialists were protected, the faculty members who were affected were highly paid tenured individuals whose productivity was out of balance with their salary.

The first implication stresses the necessity to incorporate disciplinary constraints into formula-driven and optimization models. One of the conclusions of this study was that disciplines could be structured around recognized discipline elements with a critical number of key specialists required to preserve and lead these elements. Failure to recognize that fact could either cause irreparable damage to a discipline or encourage management-by-crisis situations.

Second. Court rulings have made it clear that tenured faculty members are not exempt from dismissals in times of financial stringency. There was a time where the dismissal of tenured faculty meant dismissal for "adequate cause" only; "cause" was believed to exclude the loss of faculty positions due to financial emergency. Faculty termination cases brought in front of the courts in the 1970's have indicated that an institution is on relatively safe ground once she has established financial exigency and followed the "minimal procedures" in dismissal actions.

Third. In a period of declining enrollments, an institution would be faced with the following dilemna: either she reduces her faculty by going along with the usual seniority system scheme argued by collective bargaining units and possibly jeopardizes her mission 
61 Managerial and Disciplinary Constraints Applied to Faculty Staffing

and vitality or she demonstrates (most probably in a court of law) that her decision not to follow that scheme is a reasonably calculated measure to save the stability of a department and its academic programs.

Fourth. Contractual agreements between faculty members and institutions should be made more specific to take into account the key specialist/specialist variable. It would make it easier for both parties to clarify mutual expectations and thereafter to assess performances.

The author is indebted to Drs F. Craig Johnson and Morgan A. Hanson respectively professors in the departments of Educational Management Systems and Statistics at Florida State University. A note of thanks is also extended to the department chairmen who made this study possible.

\section{REFERENCES}

Andrew, G.M., and Collins, R., "Matching Faculty to Courses," College and University, Vol. 46 (Winter, 1971), pp. 83-89.

Bartholomew, D.J., A Mathematical Analysis of Structural Control in a Graded Manpower System, Report P4, Ford Research Program in University Administration, University of California, Berkeley, 1969.

Belanger, C.H., The Impact of Disciplinary Constraints upon Models Used to Optimize Faculty Resource Allocation, (Ph.D. dissertation, Florida State University, December 1974)

Geoffrion, A.M., Dyer, J.S. and Feinberg, A., "An Interactive Approach for Multi-Criterion Optimization, with an Application to the Operation of an Academic Department," Management Science, Vol. 19 (December, 1972), Part 1, pp. 357-368.

Heinlein, A.C., (ed.), Decision Models in Academic Administration, (Kent, Ohio: The Decision Science Institute of the Centre for Business and Economic Research, 1973).

Hopkins, D.S.P., "Faculty Early Retirement Programs," Operations Research, Vol. 22 (May-June, 1974), pp. 455467.

Hussain, K.M. and Mason, T.R., "Planning Models in Higher Education: A Comparison of Campus and RRPM," Tomorrow's Imperative Today - Proceedings of the 13th Annual Forum, Edited by Robert G. Cope, Vancouver, British Columbia: The Association for Institutional Research, 1973.

Mason, T.R., (ed.), Assessing Computer-Based Systems Models, (San Francisco: Jossey-Bass Inc., 1976).

McNamara, J.F., "Operations Research and Educational Planning," Journal of Data Processing, Vol. 9 (1972), pp. 1-12.

Oliver, R.M., An Equilibrium Model of Faculty Appointments, Promotions and Quotas Restrictions, Report 69-10, Ford Research Program in University Administration, University of California, Berkeley, 1969.

"On Institutional Problems Resulting from Financial Exigency: Some Operating Guidelines." AAUP Bulletin, Vol. 60 (June, 1974), p. 267.

Organization for Economic Cooperation and Development, Mathematical Models for the Education Sector - A Survey, (Paris: OECD, 1973).

Organization for Economic Cooperation and Development, Mathematical Models for the Education Sector - Supporting Material to the Survey, (Paris: OECD, 1974).

Organization for Economic Cooperation and Development, Institutional Resource Allocation Models in Higher Education, (Paris: OECD, 1977).

Organization for Economic Cooperation and Development, Management Information Systems for Higher Education, (Paris: OECD, 1977). 
Perlman, D.H., "New Tools and Techniques in University Administration," Educational Record, Vol. 55 (Winter, 1974), pp. 34-42.

Plessner, Y., Fox, K.A. and Sanyal, B.C., "On the Allocation of Resources in a University Department," Metroeconomica, Vol. 20 (September-December, 1968), pp. 256-271.

Rowe, S., Wagner, W.G. and Weathersby, G.B., A Control Theory Solution to Optimal Faculty Staffing, Report P-11, Ford Research Program in University Administration, University of California, Berkeley, 1970.

Ruffer, D.G. and Shabanowitz, H., "The Critical Number of Faculty - A Model," Planning for Higher Education, Vol. 6 (June, 1978).

Shoemaker, W.A., Systems Models and Programs for Higher Education, (Washington, D.C.: The Academy for Educational Development, Inc., 1973).

Tillett, P.I., "An Operations Research Approach to the Assignment of Teachers to Courses," SocioEconomic Planning Sciences, Vol. 9 (June, 1975), pp. 101-104.

Turksen, I.B. and Holzman, A.G., "Micro Level Resource Allocation Models for Universities," Operations Research, Vol. 18 (April, 1970), Supplement 1, p. B-39.

Von Zur-Muehlen, M., The Canadian Universities in a Crisis, (Ottawa: Statistics Canada, 1977). 